\title{
PENERAPAN MANAJEMEN BERBASIS AKTIVITAS UNTUK MENINGKATKAN EFISIENSI BIAYA PADA WHIZ PRIME HOTEL MEGAMASS MANADO
}

\author{
Ester R. Kalonio ${ }^{1}$, Agus T. Poputra ${ }^{2}$, Victorina Z. Tirayoh ${ }^{3}$ \\ ${ }^{1,2,3}$ Fakultas Ekonomi dan Bisnis, Jurusan Akuntansi, Universitas Sam Ratulangi, Jl. Kampus Bahu, Manado, \\ 95115, Indonesia \\ E-mail : erkolonio@gmail.com
}

\begin{abstract}
The success of a company is largely determined by the accuracy of the leadership abilities in the management of the company. Cost efficiency has significance for the company in maintaining its existence in the business world. Activity Based Management is a method to achieve efficiency. The purpose of this research is to apply activity-based management method at Whiz Prime Hotel Megamass Manado by analyzing various activities in each deparment in hotel. The method used in this research is quantitative descriptive method. The results of this research is found some activities that are non value added activity in some departments in Whiz Prime Hotel Megamass Manado. However, after the implementation of activity management, the cost is not added value at each activity that does non value activity in some departments can be eliminated or reduced by Rp. 561.141.884. Thus, management can make cost reductions, so the company becomes more efficient.
\end{abstract}

Keyword: Efficiency, Activity Based-Management, Non Value Added Activity.

\section{PENDAHULUAN}

Kemajuan yang sangat pesat pada dunia usaha dewasa ini tidak terlepas dari kemajuan teknologi diberbagai bidang. Ini telah memacu terciptanya lingkungan usaha yang maju. Kemajuan tersebut akan mendorong perkenomian, baik ditingkat nasional maupun internasional. Dalam globalisasi kemajuan ini juga membawah dampak berupa persaingan bisnis yang semakin ketat. Sebab Persaingan terjadi bukan hanya dengan perusahaan domestik namun juga dengan perusahaan di luar negeri. Peningkatan usaha sudah sangat terasa bagi perusahaan, baik itu perusahaan jasa, perdagangan, maupun manufaktur.

Keberhasilan suatu perusahaan adalah sangat ditentukan oleh kecermatan atas kemampuan pimpinan dalam pengelolaan perusahaan. Suatu perusahaan yang baik dalam pencapaian tujuan memerlukan pedoman yang mengarahkan kegiatan - kegiatan manajemen pada pencapaian tujuan yang dimaksud.

Beberapa cara yang sering digunakan oleh pihak manajemen perusahaan, untuk mencapai keunggulan dalam persaingan yaitu dengan berfokus pada peningkatan proses dan aktivitas mereka, perhatian terhadap kualitas, fleksibilitas, dan efisiensi biaya. Selama ini perusahaan cenderung menerapkan sistem akuntansi tradisional yang terbukti memiliki banyak kelemahan dan tidak lagi sesuai dengan kondisi perusahaan yang beroperasi dalam lingkungan yang dinamis karena hanya berfokus pada pengelolaan biaya dan pengalokasian biaya overhead pabrik ke produk dan pelanggan didasarkan pada volume produksi seperti jam kerja langsung, jam mesin, dan bahan baku. Padahal tidak semua pemicu biaya adalah volume produksi, tetapi aktivitaslah yang menyebabkan biaya.

Pengelolaan aktivitas (activity management) merupakan suatu proses pengidentifikasian aktivitas yang dijalankan oleh perusahaan, penentuan nilainya bagi perusahaan, pemilihan serta pelaksanaan aktivitas yang menambah nilai bagi konsumen, mengidentifikasikan atau menghilangkan semua aktivitas tak bernilai tambah sehingga menghasilkan penurunan biaya pengidentifikasian aktivitas ini dapat dibagi 2 (dua) yaitu aktivitas yang bernilai tambah (value added activity) dan aktivitas yang tak bernilai tambah (non value activity). 
Metode untuk mengelola aktivitas tersebut dinamakan manajemen berdasarkan aktivitas (activity-based management). Manajemen berdasarkan aktivitas adalah pendekatan untuk keseluruhan sistem yang terintegrasi dan berfokus pada perhatian manajemen atas berbagai aktivitas dengan tujuan meningkatkan nilai bagi pelanggan dan laba yang dicapai dengan mewujudkan nilai ini. Manajemen berdasarkan aktivitas meliputi analisis perhitungan biaya produk berdasarkan aktivitas memberikan informasi mengenai biaya sumber daya, aktivitas, produk, dan pelanggan. Penentuan biaya sumber daya yang tepat dan akurat dapat ditelusuri ke aktivitas - aktivitas kemudian biaya aktivitas tersebut dibebankan ke produk dan pelanggan. Sedangkan analisis nilai dan proses memberikan informasi tentang aktivitas apa saja yang dilakukan, mengapa aktivitas tersebut dilakukan, dan bagaimana pelaksanaan aktivitas tersebut.

Perusahaan jasa adalah perusahaan yang mempunyai kegiatan utama memberikan pelayanan kemudahan dan kenyamanan kepada masyarakat untuk memperlancar aktivtias produksi maupun konsumsi. Jasa yang dihasilkan bersifat abstrak tapi bisa dirasakan manfaatnya oleh konsumen.

Penerapan manajemen berbasis aktivitas tidak hanya diterapkan pada perusahaan manufaktur semata, tetapi juga untuk perusahaan jasa dimana salah satunya adalah perusahaan perhotelan.

Dengan tersedianya fasilitas - fasilitas penunjang akan menyebabkan berkembangnya kegiatan operasional hotel. Keberhasilan dari industri jasa ini dapat dinilai dari kepuasan pelanggan yang menggunakan jasa tersebut. Oleh karena itu, untuk dapat bertahan atau memenangkan persaingan, para pengelola harus dapat menciptakan dan meningkatkan keunggulan kompetitif dengan membangun keakraban antara pengguna dan pemberi jasa serta melakukan perbaikan secata terus menerus (continuous improvment) agar dapat memenuhi harapan dan ekspetasi pelanggan. Apabila ekspetasi pelanggan ini tercapai, maka kepuasan dari pelanggan tersebut akan tercapai pula. Kepuasan pelanggan inilah yang akan menjadi kunci yang sangat menentukan dalam meraih keunggulan kompetitif.

Perkembangan perhotelan Kota Manado berkembang dengan pesat, baik hotel berbintang maupun hotel melati. Perkembangan tersebut baik pada jumlah hotel maupun jumlah kamar, serta jasa - jasa lain yang diberikan. Hal tersbut menyebabkan persaingan antar hotel semakin ketat. Untuk memenangkan persaingan tersebut, manajemen perlu menerapkan strategi untuk memenangkan persaingan tanpa mengorbankan laba. Salah satu strategi yang dapat diterapkan untuk maksud ini adalah manajemen berbasis aktivitas. Lewat Manajemen Berbasis Aktivitas, manajemen dapat melaksanakan efisiensi tanpa mengorbankan layanan. Ini dikarenakan Manajemen Berbasis Aktivitas dapat membantu manajemen menghilangkan biaya - biaya yang bersumber dari aktivitas yang tidak menambah nilai (non value added activity).

Whiz Prime Hotel Megamass Manado adalah salah satu hotel berbintang tiga yang ada di kota Manado. Berdasarkan dengan interview dengan bagian accounting pada hotel tersebut sistem akuntansi yang selama ini dipakai pada tiap departemen adalah perhitungan berdasarkan volume produksi tanpa memperhatikan aktivitas yang memicu timbulnya biaya tersebut sehingga pembebanan biaya menjadi tidak efisien. Tujuan penelitian ini adalah untuk menganalisis penerapan Manajemen Berbasis Aktivitas dalam rangka meningkatkan efisiensi biaya pada Whiz Prime Hotel Megamass Manado.

\section{TINJAUAN PUSTAKA}

\subsection{Akuntansi}

Menurut Harahap (2011:5) “Akuntasi adalah menyangkut angka - angka yang akan dijadikan dasar dalam proses pengambilan keputusan, angka itu menyangkut uang atau nilai moneter yang mengambarkan catatan dari transaksi perusahaan. Angka itu dapat dianalisis 
lebih lanjut untuk menggali lebih banyak informasi yang dikandungnya dan memprediksi masa yang akan datang, ia bersifat netral kepada semua pemakai laporan, ada unsur seninya karena berbagai alternatif yang dipilih melalui pertimbangan subjektif serta ia merupakan informasi yang sangat diperlukan para pemakai untuk pengambilan keputusan. Nugroho (2009:123), akuntansi adalah proses dari tiga kegiatan : mengidentifikasi, merekam dan mengkomunikasikan peristiwa ekonomi suatu organisasi (bisnis atau non bisnis) kepada pengguna yang berminat akan informasi akuntansi.

\subsection{Akuntansi Manajemen}

Nopalia et. al (2012:42) mengemukakan bahwa akuntansi manajemen merupakan jaringan penghubung yang sistematis dalam penyajian informasi yang berguna dan dapat daya untuk membantu pimpinan perusahaan dalam usaha mencapai tujuan organisasi yang telah diterapkan. Sujarweni (2015:1) dalam bukunya akuntansi biaya juga mendefinisikan bahwa akuntansi manajemen adalah salah satu bidang ilmu akuntansi yang mempelajari bagaimana cara menghasilkan informasi keuangan untuk pihak manajemen yang selanjutnya akan digunakan untuk pengambilan keputusan. Umumnya informasi yang dihasilkan sifatnya lebih dalam dan biasanya tidak dipublikasikan.

\subsection{Sistem Akuntansi Manajemen}

Wirjono (2013:37) sistem akuntansi manajemen merupakan sistem yang didesain secara formal untuk menyediakan informasi yang diperlukan oleh manajer dalam rangka mendukung pengambilan keputusan dan ecaluasi aktivitas manajerial. Erviana (2010:134) menjelaskan bahwa sistem akuntansi manajemen adalah suatu mekanisme pengendalian organisasi serta merupakan alat yang efektif dalam menyediakan informasi yang berguna untuk memprediksi konsekuensi yang mungkin terjadi dari berbagai alternatif yang dapat dilakukan.

\subsection{Pengertian Aktivitas}

Hansen dan Mowen (2009:48) mendefinisikan aktivitas sebagai berikut: " aktivitas adalah unit kerja yang dilakukan dalam sebuah organisasi dan dapat juga digambarkan sebagai suatu pengumpulan tindakan dalam suatu organisasi bagi para manajer untuk melakukan perencanaan, pengendalian, dan pengambilan keputusan".

\subsection{Analisis Aktivitas}

\subsubsection{Pengertian Analisis Aktivitas}

Horngren et al (2008:89) analisis aktivitas adalah proses pengidentifikasian biaya yang tepat dan pengaruhnya terhadap biaya pembuatan prosuk atau penyediaan layanan.

\subsubsection{Tahap - Tahap Pelaksanaan Aktivitas}

Menurut Atkinson yang dikutip dalam Sitorus mengungkapkan (2014:1003) secara spesifik analisis aktivitas dapat dilaksanakan melalui 4 tahap yaitu sebagai berikut:

a. Identifikasi tujuan proses

Tujuan dari proses ini diketahui dari keinginan atau harapan konsumen dari proses tersebut.

b. Pencatatan aktvitas

Mencatat seluruh aktivtias yang digunakan untuk produk atau jasa dari awal sampai akhir.

c. Klasifikasi

Mengklasifikasikan seluruh aktivitas sebagai value added maupun non value added

d. Meningkatkan efisiensi seluruh aktivitas dan merencanakan aktivitas yang tak bernilai tambah secara berkesinambungan. 


\subsubsection{Biaya Aktivitas}

Biaya aktivitas adalah biaya total dari semua elemen - elemen biaya yang diperlukan untuk melakukan suatu aktivitas. Perhitungan biaya aktivitas ini dilakukan setelah aktivitas organisasi selesai diidentifikasi dan ditetapkan. Untuk itu aktivitas - aktivitas perlu dianalisis satu per satu agar dapat diketahui berapa besar biaya yang dikonsumsi oleh masing - masing aktivitas tersebut dan bagaimana kinerja serta kontribusi tiap - tiap aktivitas bagi perusahaan. Langkah - langkah yang dapat dilakukan untuk menghitung besarnya biaya yang dikeluarkan untuk sebuah aktivitas pada sebuah perusahaan yaitu sebagai berikut:
a. Memilih dasar biaya
b. Menelusuri sumber biaya
c. Mementukan pasar pemicu biaya
d. Menghitung biaya aktivitas.

\subsection{Definisi Activity Based Costing}

Susanto (2012:9) mengungkapkan bahwa activity based costing memiliki tujuan penyediaan informasi bagi semua pihak yang terlibat dalam pengambilan keputusan dan pemberdayaan karyawan untuk membangun daya saing perusahaan. Suratinoyo (2013:661) mengungkapkan bahwa activity based costing merupakan salah satu upaya meningkatkan akurasi informasi biaya dari sistem akuntansi biaya konvensional.

\subsection{Aktivitas Bernilai Tambah dan Tidak Bernilai Tambah 2.7.1 Aktivitas Bernilai Tambah}

Berbagai aktivitas yang dibituhkan untuk dapat bertahan dalam bisnis disebut sebagai aktivitas yang bernilai tambah (Hansen dan Mowen 2009:237).

\subsubsection{Aktivitas Tak Bernilai Tambah}

Semua aktivitas selain berbagai aktivitas yang paling penting untuk tetap bertahan dalam bisnis sehingga dipandang tidak perlu, disebut sebagai aktivitas tak bernilai tambah (Hansen dan Mowen 2009:238).

\subsection{Manajement Berbasis Aktivitas (Activity Based Management)}

Hasen dan Mowen (2009:13) menyatakan juga bahwa manajemen berdasarkan aktivitas (activity based management) adalah suatu pendekatan yang teritegrasi di seluruh sistem yang memfokuskan perhatian manajemen pada berbagai aktivitas yang bertujuan meningkatkan nilai bagi pelanggan dan laba yang dihasilkan. Bangun (2006:248), ABM adalah pendekatan pengelolaan terpadu dan bersistem terhadap aktivitas dengan tujuan untuk meningkatkan costomer value dan laba yang dicapai dari penyediaan value tersebut.

\subsection{Manajemen Berbasis Aktivitas Pada Perusahaan Jasa Perhotelan}

\subsubsection{Karakterisitk Perusahaan Jasa}

Jasa merupakan produk dalam bentuk pelayanan dimana output yang dihasilkan dalam bentuk tidak berwujud. Jasa memiliki 4 karakteristik utama yaitu sebagai berikut:

a. Intangibility

Intangibility artinya tidak berwujud. Intangibility adalah karakteristik utama yang membedakan antara produk dan jasa. Adanya karakteristik ini membuat pembeli tidak dapat membeli, merasaka, mendengar, atau merasakan jasa sebelum mereka membelinya.

b. Perishability

Perishability artinya jasa tak perlu disimpan atau digunakan di masa yang akan dating tetapi harus langsung dikonsumsi ketika jasa tersbut dihasilkan.

c. Inseperability

Inseperability secara harfiah artinya tidak biasa dipisahkan. Artinya konsumen dan pernjual harus mengadakan kontak langsung saat terjadinya transaksi jasa.

d. Heterogeneity 
Heterogeneity memiliki makna beragam. Artinya terdapat kemungkinan yang lebih besar dalam variasi kinerja pelayanan jasa dari pada proses produksi untuk menghasilkan suatu produk.

\subsubsection{Pengertian Hotel}

Hotel merupakan salah satu badan usaha yang bergerak dibidang jasa penginapan yang dikelolah secara komersial dan memerlukan pengelolaan secara professional terhadap sumber dana dan sumber daya manusia dalam menghasilkan jasa dengan biaya yang efisien.

\subsection{Penelitian Terdahulu}

Farida Aryani, SE., Msi., - Tria Oktarina, SE. (2016) dalam penelitian : penerapan activity based system (ABM) untuk meningkatkan efisiensi produksi pada PT. Gunung Mas Plantations IX Gunung Batin Lampung Tengah. Dari hasil penelitian biaya produksi pada tiap departement mengalami peningkatan setiap tahun. Setelah menggunakan ABM, dapat diketahui mana biaya yang bisa direduksi ataupun dieliminasi. Persamaan dalam penelitian kali ini menilai efisiensi biaya. Perbedaan dalam penelitian kali ini adalah objek penelitian dan jenis aktivitas yang ditelitih.

\section{METODE PENELITIAN}

\subsection{Jenis Penelitian}

Penelitian kali ini bersifat deskriptif. Sugiyono (2009:29) menyatakan bahwa metode penelitian deskriptif adalah suatu metode yang berungsi untuk mendeskripsikan atau memberikan gambaran terhadap objek yang diteliti melalui data atau sampel yang telah terkumpul sebagaimana adanya tanpa melakukan analisis dan kesimpulan yang berlaku umum. Penelitian ini dilakukan pada Whiz Prime Hotel Megamass Manado, dengan mengidentifikasi semua aktivitas yang berada di tiap - tiap departemen hotel selanjutnya menggelompkkan setiap aktivitas tersebut apakah bernilai tambah atau tidak bernilai tambah. Aktivitas yang tidak bernilai tambah akan dieliminasi. Data yang digunakan dalam penelitian kali ini adalah data kuantitatif.

\subsection{Prosedur Penelitian}

a. Menentukan rumusan masalah

b. Mencari informasi yang mendukung penelitian

c. Menentukan metode penelitian

d. Membuat kesimpulan

e. Memberikan saran.

\subsection{Teknik Pengumpulan Data}

Teknik pengumpulan data pada penilitian kali ini adalah mengunjugi objek penelitian kemudian melakukan observasi dimana mengumpulkan data ddnegan melakukan pengamatan secata lagsung terhadap objek penelitian, dan melakukan interview dengan pihak manajemen hotel.

\subsection{Meode Analisis}

Metode analisis yang digunakan dalam penelitian kali ini adalah menggunakan metode analisis deskriptif dimana data perusahaan yang telah terkumpul, nantinya akan disusun dan diolah, kemudian di analisis dan dibandingkan dengan teori - teori yang ada selama ini.

\section{HASIL PENELITIAN DAN PEMBAHASAN \\ 4.1 Gambaran Umum Objek Penelitian \\ 4.1.1 Profil Objek Penelitian.}

Whiz Prime Hotel Megamas Manado Departemen (WPMD) berada dibawah Intiwhiz Hospitality Management, yang merupakan salah satu jaringan hotel terkemuka di Indonesia. WPMD merupakah hotel ke 13 dari sekitar 50an hotel yang direncanakan akan terus dibangun, dan tersebar di seluruh kota - kota besar di Indonesia. WPMD dibuka pada tanggal 
11 November 2015, diresmikan oleh Presiden Komisaris PT. Intiland, Bapak Cosmas Batubara, Pemilik Whiz Internasional Bapak Ir. Moedjianto Tjahjono MBA, General Manager Sales Marketing Bapak Edi Syumardi dan Manajer Whiz Prime Megamas Manado Bapak Yushi Quan. Whiz Prime Hotel Megamass Manado berlokasi di Kawasan Megamass, Jalan Piere Tendean Boulevard Manado, Indonesia 95111. Terletak di kawasan elit kota Manado, dekat dengan pusat ibadah, pusathiburan, pusat perbelanjaan, dan pusat kuliner.

\subsubsection{Fasilitas Pendukung}

Selain kamar, fasilitas yang ada di Whiz Prime Hotel Megamass Manado adalah :

a. Meeting Room : Katrili, Maengket, dan Cakalele

b. Napoleon Restaurant : Hanya untuk sarapan pagi.

c. Kolam Renang

d. Resepsionis 24 jam

e. Keamanan 24 jam

f. Surat kabar di lobby

g. Layanan Spa

h. Wifi

\subsection{Hasil Penelitian}

\subsubsection{Penyajian Biaya Divisi}

Biaya - biaya divisi ini timbul dari semua biaya yang berkaitan dengan aktivitas pemberian jasa penginapan yaitu mulai dari administration and general department, sales and marketing department, food and beverage department, room department (front office and house keeping), and engenering department. Data biaya tiap departement selama tahun 2016 ini diperoleh dari bagian accounting hotel selama tahun 2016.

Tabel 1 Biaya - biaya divisi room Whiz Prime Hotel Megamas Manado Tahun 2016

\begin{tabular}{|c|c|}
\hline Jenis biaya & Jumlah biaya (Rp) \\
\hline Salaries & 2.030 .000 .000 \\
\hline Kebersihan & 72.000 .000 \\
\hline Keamanan & 384.000 .000 \\
\hline Listrik & 1.440 .000 .000 \\
\hline Air & 132.000 .000 \\
\hline Internet + Telepon & 390.000 .000 \\
\hline Bahan bakar & 24.500 .000 \\
\hline Fb catering & 1.236 .500 .000 \\
\hline Printing \& stationary & 64.700 .000 \\
\hline Maintenance & 382.000 .000 \\
\hline Promotion & 62.500 .000 \\
\hline Laundry & 205.000 .000 \\
\hline Cleaning supplies & 72.800 .000 \\
\hline
\end{tabular}

Sumber : data internal perusahaan

\subsection{Pembahasan}

\subsubsection{Analisis Aktivitas}

Setelah perhitungan pembebanan biaya ke aktivitas tiap departemen diketahui maka dilakukan analisis terhadap aktivitas di tiap departemen. Hal ini dilakukan untuk menentukan aktivitas apa saja yang bernilai tambah dan aktivitas apa saja yang tidak bernilai tambah. Untuk mengklasifikasikan aktivitas ini menjadi aktivitas bernilai tambah atau tidak bernilai tambah, maka sesuai dengan teori yang menjelaskan bahwa aktivitas bernilai tambah merupakan aktivitas yang secara keseluruhkan memenuhi tiga kondisi yaitu sebagai berikut:

a. Aktivitas tersebut menghasilkan suatu perubahan. 


\section{b. Perubahan tersebut tidak dapat dicapai oleh aktivitas yang sebelumnya. \\ c. Aktivitas tersebut memungkinkan aktivitas lain untuk dilakukan.}

\subsubsection{Aktivitas Bernilai Tambah dan Tidak Bernilai Tambah}

Dari analisis aktivitas tersebut diatas dapat digunakan untuk penentuan aktivitas yang bernilai tambah (value added actvity) dan tidak bernilai tambah (non value added activity). Untuk selanjutnya dari pengelompokkan biaya tersebut dapat di eliminasi ataupun direduksi sehingga biaya yang tidak bernilai tambah yang muncul dari aktivitas yang tidak bernilai tambah dapat dikurangi.

Tabel 2 Biaya Value Added Activities dan Non Value Added Activities

\begin{tabular}{|c|c|c|c|}
\hline Jenis Aktivitas Tiap Departemen & VA (Rp) & NVA (Rp) & Total (Rp) \\
\hline \multicolumn{4}{|l|}{ Administration and General } \\
\hline \multicolumn{4}{|l|}{ Accounting } \\
\hline Menerima dan mengelolah uang dari setiap section & $68,278,175$ & & $68,278,175$ \\
\hline Audit pendapatan dan pengeluaran & $452,278,175$ & & $452,278,175$ \\
\hline Melakukan perijinan hotel. & $49,335,318$ & & $49,335,318$ \\
\hline Pebayaran ke pihak ketiga. & $67,124,675$ & & $67,124,675$ \\
\hline Pembayaran kebutuhan hotel. & $48,181,818$ & & $48,181,818$ \\
\hline Pendataan inventaris hotel. & $50,490,318$ & & $50,490,318$ \\
\hline \multicolumn{4}{|l|}{ HRD } \\
\hline 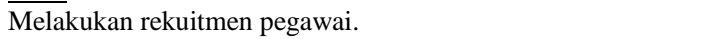 & $68,278,193$ & \multirow{6}{*}{$50,490,318$} & $68,278,193$ \\
\hline Menyiapkan kebutuhan kerja karyawan. & $67,124,693$ & & $67,124,693$ \\
\hline Pelaporan dan update data karyawan. & $70,585,193$ & & $70,585,193$ \\
\hline Mengelolah penggajian karyawan. & $69,433,193$ & & $69,433,193$ \\
\hline Mengelolah absensi karyawan. & & & $50,490,318$ \\
\hline \multicolumn{3}{|l|}{ Sales and Marketing Departement } & \\
\hline Penjulan produk hotel. & $171,185,000$ & & $171,185,000$ \\
\hline Membuat perencanaan dan pelaksanaan promosi. & $133,580,000$ & & $133,580,000$ \\
\hline Menjaga hubungan baik dengan klien. & $101,035,000$ & & $101,035,000$ \\
\hline \multicolumn{4}{|l|}{ Food and Beverage Departement } \\
\hline Melakukan persiapan peralatan makan dan minum. & $310,636,800$ & \multirow{4}{*}{$45,021,800$} & $310,636,800$ \\
\hline Control terhadap menu dan tamu yang menginap. & $940,488,800$ & & $940,488,800$ \\
\hline Mejaga kebersihan restoran. & \multirow{4}{*}{$13,113,800$} & & $45,021,800$ \\
\hline Pelayanan sesuai dengan kebutuhan tamu. & & & $13,113,800$ \\
\hline Menyambut tamu yang datang dan pergi. & & $10,138,800$ & $10,138,800$ \\
\hline \multirow{2}{*}{\multicolumn{4}{|c|}{$\begin{array}{l}\text { Koom Departement ( Front Unice and House Keeping) } \\
\text { Front Office }\end{array}$}} \\
\hline & & & \\
\hline Adninistrasi tamu yang check in dan check out. & $45,222,800$ & \multirow{7}{*}{$62,847,000$} & $45,222,800$ \\
\hline Menerima reservasi individual atau grup. & $43,666,000$ & & $43,666,000$ \\
\hline Menangani permintaan tamu yang menginap. & $40,555,200$ & & $40,555,200$ \\
\hline Menangani telepon yang masuk. & $90,693,600$ & & $90,693,600$ \\
\hline Konfirmasi reservasi kamar. & & & $62,847,000$ \\
\hline Menangani pembayaran kamar. & $34,986,000$ & & $34,986,000$ \\
\hline Permintaan showing room. & $62,847,000$ & & $62,847,000$ \\
\hline Permintaan wake up call tamu & & $51,693,600$ & $51,693,600$ \\
\hline Permintaan penitipan barang. & & $34,986,000$ & $34,986,000$ \\
\hline Melakukan postingan tiap transaksi. & $34,986,000$ & & $34,986,000$ \\
\hline Penanganan keluhan tamu. & $46,124,400$ & & $46,124,400$ \\
\hline \multicolumn{4}{|l|}{ House Keeping } \\
\hline Pembersihan kamar, meeting room, area umum, area karyawan. & $374,066,000$ & \multirow{4}{*}{$34,986,000$} & $374,066,000$ \\
\hline Penggantian status kamar. & $38,096,800$ & & $38,096,800$ \\
\hline Penangan VIP sesuai permintaan. & & & $34,986,000$ \\
\hline Permintaan peminjaman barang. & $34,986,000$ & & $34,986,000$ \\
\hline Permintaan pencucian pakaian. & $92,386,000$ & \multirow{4}{*}{$120,692,000$} & $92,386,000$ \\
\hline Pencucian linen hotel & $182,586,000$ & & $182,586,000$ \\
\hline Melakukan pembersihan area. & & & $120,692,000$ \\
\hline Melakukan Inspeksi Kamar & $73,082,800$ & & $73,082,800$ \\
\hline \multicolumn{4}{|l|}{ Engenering department } \\
\hline Pemeliharaan hotel. & $86,961,400$ & \multirow[b]{3}{*}{$45,044,600$} & $86,961,400$ \\
\hline Perbaikan kamar apabila ada kerusakan. & $65,061,400$ & & $65,061,400$ \\
\hline Pengecatan bangunan. & & & $45,044,600$ \\
\hline Melakukan pembelian dan perbaikan barang & $129,900,600$ & & $129,900,600$ \\
\hline Perawatan air kolam & $106,086,399$ & & $106,086,399$ \\
\hline Pencucian filter kolam renang. & $106,086,399$ & & $106,086,399$ \\
\hline Melakukan back wash filter kolam renang. & & $106,086,399$ & $106,086,399$ \\
\hline Melakukan instalasi peralatan. & $638,086,400$ & & $638,086,400$ \\
\hline Pengelasan terhadap barang - barang yang rusak. & $926,086,400$ & & $926,086,400$ \\
\hline Total & $5,933,702,749$ & $561,986,517$ & $6,495,689,266$ \\
\hline Dibulatkan & $5,933,858,116$ & $562,141,884$ & 6.496 .000 .000 \\
\hline
\end{tabular}

Sumber : data olahan 
Dari keterangan diatas maka besarnya pengurangan biaya yang terjadi akibat adanya manajemen aktivitas ini adalah:

a. Mengelolah absensi karyawan akan di eliminasi sebesar $100 \%$, sehingga biaya yang berkurang adalah sebesar Rp. 50.490.318.

b. Menjaga kebersihan restoran akan dieliminasi sebesar 100\%, akibatnya akan terjadi pengurangan biaya sebesar Rp. 45.021.800.

c. Aktivitas menyambut tamu yang datang dan pergi akan dieliminasi sebesar $100 \%$, akibatnya akan terjadi pengurangan biaya untuk aktivitas ini sebesar Rp. 10.138.800.

d. Aktivitas konfirmasi revervasi kamar juga dieliminasi $100 \%$ berarti biaya yang dapat dikurangi sebesar Rp. 62.847.000

e. Permintaan wake up call tamu juga akan dieliminasi sebesar $100 \%$, maka biaya untuk aktivitas ini berkurang menjadi Rp. 51.693.600.

f. Aktivitas permintaan penitipan barang dieliminasi sebesar $100 \%$, sehingga biaya dapat berkurang menjadi Rp. 34.986.000.

g. Penangan VIP sesuai permintaan dieliminasi sebesar $100 \%$, maka biaya untuk aktivitas ini dapat berkurang sebesar Rp. 34. 986.000.

h. Melakukan pembersihan area juga dieliminasi sebesar $100 \%$, berarti biaya yang dapat dikurangi sebesar Rp. 120.692.000.

i. Pengecatan bangunan juga dieliminasi $100 \%$ sehingga biaya yang dikurangi adalah Rp. 45.044.600

j. Melakukan back wash filter kolam renang dieliminasi sebesar $100 \%$ sehingga biaya untuk melakukan aktivitas ini adalah sebesar Rp. 106.086.399

Dari pengeliminasian aktivitas yang tidak bernilai tambah diatas maka biaya aktivitas yang timbul tentu saja akan berkurang. Total biaya yang berkurang dapat dilihat pada tabel berikut ini:

Tabel 3 Biaya Aktivitas Setelah Cost Reduction

\begin{tabular}{|c|c|c|}
\hline Jenis Aktivitas Tiap Departemen & VA (Rp) & Total (Rp) \\
\hline \multicolumn{3}{|l|}{ Administration and General } \\
\hline Menerima dan mengelolah uang dari setiap section & 68278175 & $68078 \quad 175$ \\
\hline Audit pendapatan dan pengeluaran & 452278175 & 452278175 \\
\hline Melakukan perijinan hotel. & $49,335,318$ & $49,335,318$ \\
\hline Pebayaran ke pihak ketiga. & $67,124,675$ & $67,124,675$ \\
\hline Pembayaran kebutuhan hotel. & $48,181,818$ & $48,181,818$ \\
\hline Pendataan inventaris hotel. & $50,490,318$ & $50,490,318$ \\
\hline \multicolumn{3}{|l|}{ HRD } \\
\hline Melakukan rekuitmen pegawai. & $68,278,193$ & $68,278,193$ \\
\hline Menyiapkan kebutuhan kerja karyawan. & $67,124,693$ & $67,124,693$ \\
\hline Pelaporan dan update data karyawan. & $70,585,193$ & $70,585,193$ \\
\hline Mengelolah penggajian karyawan. & $69,433,193$ & $69,433,193$ \\
\hline \multicolumn{3}{|l|}{ Sales and Marketing Departement } \\
\hline Penjulan produk hotel. & $171,185,000$ & $171,185,000$ \\
\hline Membuat perencanaan dan pelaksanaan promosi. & $133,580,000$ & $133,580,000$ \\
\hline Menjaga hubungan baik dengan klien. & $101,035,000$ & $101,035,000$ \\
\hline \multicolumn{3}{|l|}{ Food and Beverage Departement } \\
\hline Melakukan persiapan peralatan makan dan minum. & $310,636,800$ & $310,636,800$ \\
\hline Control terhadap menu dan tamu yang menginap. & $940,488,800$ & $940,488,800$ \\
\hline Pelayanan sesuai dengan kebutuhan tamu. & $13,113,800$ & $13,113,800$ \\
\hline \multicolumn{3}{|l|}{ Room Departement (Front Office and House Keeping) } \\
\hline \multicolumn{3}{|l|}{ Front Office } \\
\hline Adninistrasi tamu yang check in dan check out. & $45,222,800$ & $45,222,800$ \\
\hline Menerima reservasi individual atau grup. & $43,666,000$ & $43,666,000$ \\
\hline Menangani permintaan tamu yang menginap. & $40,555,200$ & $40,555,200$ \\
\hline Menangani telepon yang masuk. & $90,693,600$ & $90,693,600$ \\
\hline Menangani pembayaran kamar. & $34,986,000$ & $34,986,000$ \\
\hline Permintaan showing room. & $62,847,000$ & $62,847,000$ \\
\hline Melakukan postingan tiap transaksi. & $34,986,000$ & $34,986,000$ \\
\hline Penanganan keluhan tamu. & $46,124,400$ & $46,124,400$ \\
\hline \multicolumn{3}{|l|}{ House Keeping } \\
\hline Pembersihan kamar, meeting room, area umum, area karyawan. & $374,066,000$ & $374,066,000$ \\
\hline Penggantian status kamar. & $38,096,800$ & $38,096,800$ \\
\hline Permintaan peminjaman barang. & $34,986,000$ & $34,986,000$ \\
\hline
\end{tabular}




\begin{tabular}{|l|r|r|}
\hline \multicolumn{1}{|c|}{ Jenis Aktivitas Tiap Departemen } & \multicolumn{1}{c|}{ Total (Rp) } \\
\hline Permintaan pencucian pakaian. & $92,386,000$ & $92,386,000$ \\
Pencucian linen hotel & $182,586,000$ & $182,586,000$ \\
Melakukan Inspeksi Kamar & $73,082,800$ & $73,082,800$ \\
Engenering department & & \\
Pemeliharaan hotel. & $86,961,400$ & $86,961,400$ \\
Perbaikan kamar apabila ada kerusakan. & $65,061,400$ & $65,061,400$ \\
Melakukan pembelian dan perbaikan barang & $129,900,600$ & $129,900,600$ \\
Perawatan air kolam & $106,086,399$ & $106,086,399$ \\
Pencucian filter kolam renang. & $106,086,399$ & $106,086,399$ \\
Melakukan instalasi peralatan. & $638,086,400$ & $638,086,400$ \\
Pengelasan terhadap barang - barang yang rusak. & $926,086,400$ & $926,086,400$ \\
\hline Total & $5,933,702,749$ & \\
\hline Dibulatkan & & $5,933,858,116$ \\
\hline
\end{tabular}

Sumber : Data olahan

Dengan melakukan Activity - Based Management maka total biaya di divisi room Whiz Prime Hotel Manado dapat berkurang sebanyak Rp. 561.141.884 dari Rp. 6.496.000.000 menjadi Rp. 5.933.858.116. atau sebesar $11.57 \%$.

\section{KESIMPULAN DAN SARAN}

\subsection{Kesimpulan}

Dari analisis menggunakan activity based management terhadap aktivitas - aktivitas di tiap departemen yang ada di Whiz Prime Hotel Megamass Manado, terdapat aktivitas aktivitas yang bernilai tambah dan aktivitas yang tidak bernilai tambah. Pada Whiz Prime Hotel terdapat beberapa aktivitas yang tidak bernilai tambah yang dapat menyebabkan biaya - biaya tidak bernilai tambah. Setelah dilakukan manajmen aktivitas, maka biaya tidak bernilai tambah tersebut akhirnya dapat direduksi sebesar Rp. 561.141.884. Maka dapat disimpulkan bahwa penerapan activity based management layak untuk diterapkan karena dengan penerapan metode tersebut terjadi efisiensi biaya pada departemen yang ada sehingga hal ini akan memberikan keuntungan bagi pihak hotel tanpa mengurangi jasa yang diterima oleh pelanggan.

\subsection{Saran}

Berdasarkan kesimpulan diatas sebaiknya pihak hotel untuk dapat mencapai efisiensi biaya sebaiknya berfokus pada pengelolaan aktivitas melalui penerapan activity based management supaya dapat diperoleh informasi mengenai aktivitas mana saja yang tergolong bernilai tambah atau tidak bernilai tambah sehingga pemakaian sumber daya yang tidak efisien oleh aktivitas tidak bernilai tambah tersebut dapat direduksi atau dieliminasi. Juga beberapa tindakan alternative yang dapat dilakukan pihak manajemen yaitu menggabungkan aktivitas sejenis, mereduksinya ataupun mengeliminasi aktivitas yang tidak bernilai tambah seperti mengelolah absensi karyawan, menjaga kebersihan restoran, menyambut tamu yang datang dan pergi, konfirmasi reservasi kamar, permintaan wake up call, permintaan penitipan barang, penanganan VIP sesuai permintaan, melakukan pembersihan area, pengecatan bangunan, dan melakukan back wash filter kolam renang.

\section{DAFTAR PUSTAKA}

Bangun, Prisma. 2006. Hubungan Antara Activity Based Costing, Activity Based Management and Activity Based Budgeting. Jurnal Akuntansi, Volume 6, Nomor 3, September 2006 : 245 - 256. Fakultas Ekonomi Universitas Kristen Krida Wacana.

Ervina, R. (2010). Locus Of Control, Ketidakpastian Lingkungan dan Sistem Akuntansi Manajemen. Jurnal Bisnis dan Ekonomi. Vol. 17. No. 2, September 2010. ISSN: 14123126. Universitas Islam Sultan Agung, Semarang. 
Hansen, Don R.,Mowen, Maryane M. 2009. Akuntansi Manajerial. Edisi 8. Buku 1. Salemba 4. Jakarta.

Harahap, Sofyan Syafri. 2011. Analisis Kritis Atas Laporan Keuangan, Jakarta: Raja Grafindo Persada.

Horngren, T., Datar, Srikant, M., Foster, George. 2008. Cost Accounting, A Managerial Emphasis. Twelfth Edition. International Edition. Prentice Hall Inc. New Jersey.

Nopalia. Wirmie Eka Putra. Dewi Fitriani. 2012. Pengaruh Penggunaan Informasi Akuntansi Manajemen dan Kepribadian Wirausaha Terhadap Kinerja Manajerial (Survei Pada Dealer Sepeda Motor di Kota Jambi). E-jurnal Binar Akuntansi Vol. 1 No. 1 September 2012. Jurusan Akuntansi Fakultas Ekonomi Universitas Jambi.

Nugroho, Isworo. (2009). Peranan Teknologi Informasi Dalam Audit Sistem informasi Komputerisasi Akuntansi. Dinamika Informatika. Vol. 1 No. 2. September 2009. ISSN: 2085-3343. Fakultas Tekonologi Informasi Universitas Stikubank Semarang.

Sugiyono. 2009. Metode Penelitian Kuantitatif, Kualitatif dan R\&D. Bandung. Alvabeta.

Sujarweni, V. Wiratna. 2015. Akuntansi Biaya Teori dan Penerapannya. Yogyakarta: Pustaka Baru Press.

Suratinouyo, Ayu W. 2013. Penerapan Sistem ABC Untuk Penentuan HArga Pokok Produksi Pada Bangun Wenang Beverage. Jurnal EMBA Vol 1. No. 3 September 2013, Hal. 658-668. Universitas Sam Ratulangi Manado. https://ejournal.unsrat.ac.id/index.php/emba/article/viewFile/2134/1695

Susanto, Levina. 2012. Peran Activity Based Costing Untuk Menetapkan Harga Pokok Produksi Yang Akurat. Jurnal Ilmiah Mahasiswa Akuntansi Vol. 1, No. 3, Mei 2012. Jurusan Akuntansi Fakultas Bisnis Unika Widya Madala Surabaya.

Wirjono, Endang Raino. 2013. Hubungan Antara Sistem Informasi Manajemen dan Ketidakpastian Lingkungan Yang Dirasakan Terhadap Kinerja Manajerial. Jurnal Ilmiah Akuntansi Dan Bisnis Vol. 8 N0. 1 Januari 2013. Fakultas Ekonomi Universitas Atmajaya Yogyakarta. 